ISSN: 2224-0616

Int. J . Agril. Res. Innov. \& Tech. 4 (2): 53-54, December, 2014 Available online at http://www.ijarit.webs.com

\title{
FLORAL STALK ON DATE PALM: A NEW DISCOVERY
}

\author{
P. Kumar*, S. Kiran and K. Kumar \\ Received 25 August 2014, Revised 16 November 2014, Accepted 22 December 2014, Published online 31 December 2014
}

\begin{abstract}
Date palm (Phoenix dactylifera L.) is harvested for its sweet fruit mainly in the middle east and other parts of the world. It has been cultivated for several thousand years and is known to be found in Mesopotamia as well. Besides the fruit, the various parts of the tree are employed for variety of uses. The stalks of the fruit, which connect the fruit to the spikelet, are very beautiful, colourful flower like structures, which have never been described earlier. These fruit stalks could be used for decorations in houses and would then add to more economic gain to the farmer. We observed these stalks and describe here this interesting finding hitherto unreported in the world literature.
\end{abstract}

Keywords: Date Palm, Flower, Fruit Stalk

Saham, PO Box-582, PC-319, Oman

*Corresponding author's email: kumarpramod5@rediff.com (Pramod Kumar)

\section{Introduction}

Date palm (Phoenix dactylifera L.) has been cultivated for several thousand years (Foodmuseum, 2011). Its fruit has served as a staple diet for the people living in the middle east. Date palm has been known to be cultivated in Mesopotamian civilization as well. Other parts of this tree have been described and practically all parts of the date palm except, perhaps the roots are used for a purpose best suited to them (Barreveld, 1993; Dowson, 1962). We have observed that the date fruit has a stalk attached to it similar to the green decorative cap like attachment similar to that on eggplant, which connects it to the spikelet. Once the date fruit is plucked by hand this stalk is left behind on the branch. The left over stalks on the branches gives a colourful, beautiful flower shaped structure and has not been observed earlier in the literature. We describe its existence; here for the first time.

\section{Materials and Methods}

We had been collecting dates from common Omani date palms for collecting the fruit, by cutting the branch as a whole and drying it up under the sun for several days. The dates thereafter would shrivel and fall off from the branch or plucked out easily. Thin spikelets were left on the branches. The spikelet has showed flower like, colourful, beautiful structures on them. On closer inspection it was found that this structure was sometimes absent from the spikelet and could be found on the fruit itself (Fig. $1 \& 2$ ). This structure was observed akin to the cover or stalk found over the eggplants. Several spikelets were thus observed and a similar pattern was found on all of them. Each stalk is composed of 3 petals arranged in an overlapping floral pattern and magenta colour on the edges (Fig. $3 \& 4$ ). The stalk is 7 millimeter to 8 millimeter in diameter without much variation. The petals are thin yet rigid structures not easily plucked or crushed with hands. Thus, the stalk gives a colourful, beautiful appearance to the twigs.

\section{Results and Discussion}

Date palm has been harvested for centuries. The parts other than fruit have been put to use as per their strength or structure e.g. leaflets for making brooms, spikelets to make ropes and mid ribs to make crates (Paul, 1973; Munier and Dattier, 1973; Darby et al., 1977). This beautiful floral stalk has not been described in the world literature probably because it was not observed earlier or it could not be put to a suitable use.

The presence of this stalk could have been overlooked since the humans were more focused on the fruit or other commercial gains from the tree. These stalks may be the calyx of the date flowers and hence are attached to the fruits.

The size of these stalks may vary in size according to the size of the fruit on a particular plant but will be constant for that particular plant, as we have reported this observation only for common Omani date palms. These beautiful stalks along with the twigs have been used for decoration in our house and hence could be put to such a use with its natural colour combination. 


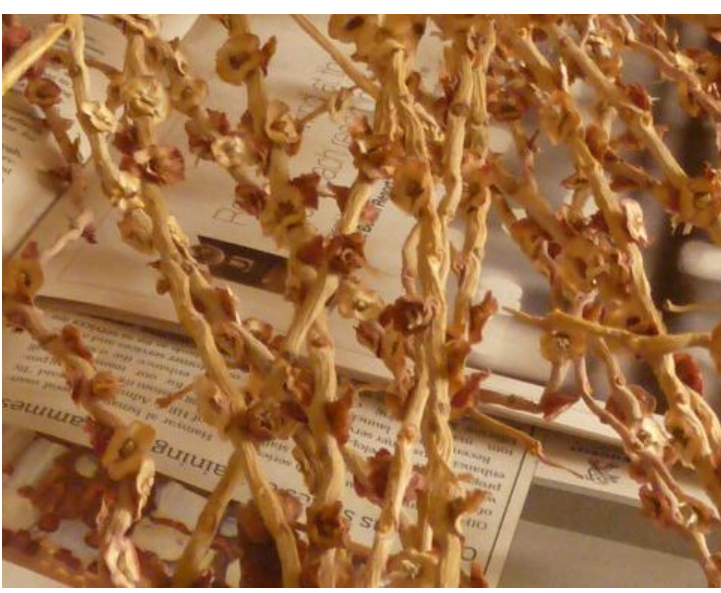

Fig. 1. Floral stalks on the twigs of branches

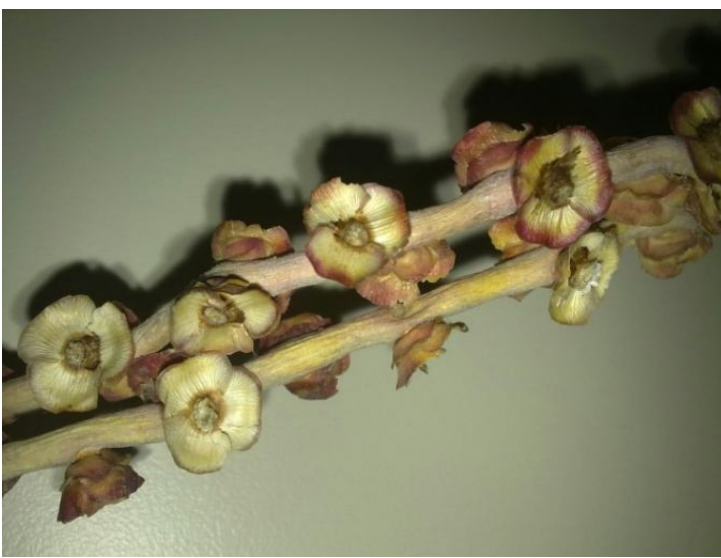

Fig. 3. Closeup of floral stalks arrange on twigs

\section{References}

Barreveld, W.H. 1993. Date palm products. Published by FAO, Rome. FAO Agricultural services Bulletin http:/ / www.fao.org/ docrep/ t0681E/ t0681e 00.htm\#con accessed on 13/08/2011.

Darby, J., Ghalioungui, P. and Grivetti, L. 1977. Food: the gift of Osiris, vol. 2. Academic Press, London.

Dowson, V.H.W. 1962. Dates-handling, processing and packing. Food and Agriculture Organization of the United

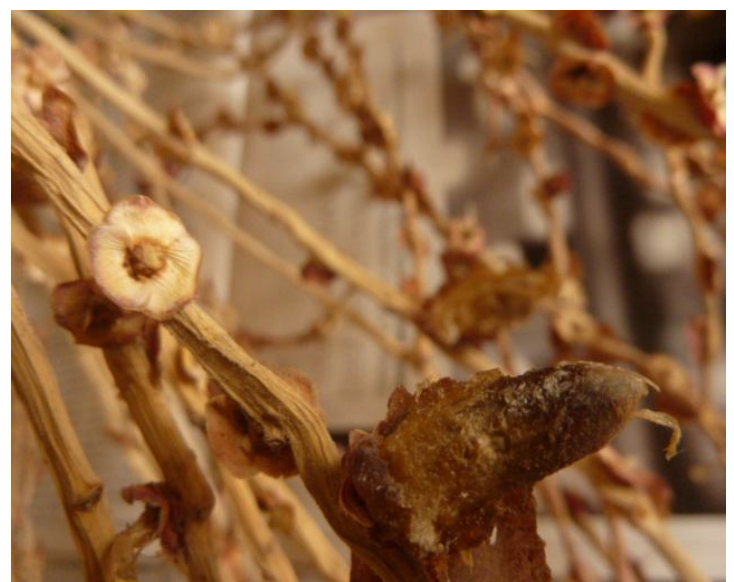

Fig. 2. Close up of a floral stalk with a date stone

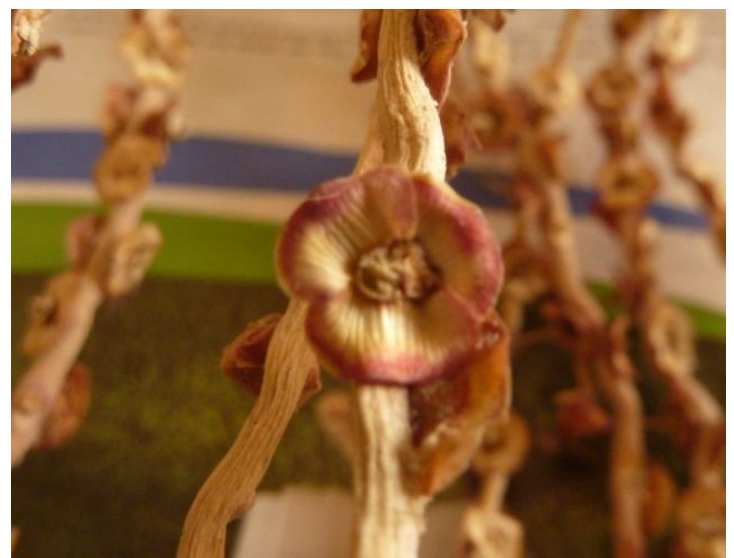

Fig. 4. Close up of a single Floral stalk

Nations, Rome. FAO Agricultural Development Paper no. 72. 392p.

http:/ / www.foodmuseum.com/ datepalm.html site accessed on 13/08/2011.

Munier, P. and Dattier, L.P. 1973. G-P Maisonneuve et Larose, Techn. Agr. \& Prod. Trop. N XXIV, paris. 221p.

Paul, P. 1973. The date palm. Edited by Henry Field. Field Research Projects, Coconut Grove, Miami, Florida, USA. pp. XII-247. 